\title{
Portal venous gas secondary to a penetrating foreign body of the stomach
}

\author{
M. A. Muñoz-Navas, MD \\ F. J. Jimenez-Perez, MD \\ F. J. Lecumberri, MD
}

From the Clinica Universitaria Navarra, Endoscopy Unit, Pamplona, Spain.

Reprints requests: F. J. Jimenez-Perez, MD, Clinica Universitaria Navarra, Endoscopy Unit, Avda Pio XII, 3631080 Pamplona, Spain.

The discovery of gas in the portal vein usually is found to be associated with intestinal necrosis. ${ }^{1}$ We report a case of portal venous gas emanating from a penetrating gastric antral ulcer, a rarely described associated condition, which in this case was caused by an accidentally swallowed toothpick that had become impaled in the stomach wall.

\section{CASE REPORT}

A 73-year-old man who had fever for 1 month also complained of anorexia, intermittent diarrhea, and headache. When admitted to our hospital, he was drowsy and disoriented. His temperature was $39^{\circ} \mathrm{C}$. Antibiotic medication had been given in preceding weeks to no avail. Ultrasonography and barium meal examination performed at another hospital reportedly revealed no defect.

The patient was found to be anemia (hemoglobin, $9.6 \mathrm{~g}$; hematocrit, 32\%), with leukocytosis (WBC, 13,800, predominantly immature neutrophils). The erythrocyte sedimentation rate was markedly elevated $(82 \mathrm{~mm})$. The serum albumin was depressed $(2.43 \mathrm{~g} / \mathrm{d} 1)$. No parasites or enteric pathogens were found at stool examination. Blood culture yielded growth of group D streptococci.

Abdominal CT examination revealed gas in the portal, splenic, and superior mesenteric veins; there was no configuration suggesting abscess or abnormality in the region of the pancreas (Fig. 1). Total colonoscopy disclosed no mucosal lesion.

At gastroscopy, a foreign body identified as a toothpick was seen to be firmly lodged in the wall of the antrum (Fig. 2). When the toothpick was extracted, a deeply penetrating ulcer was evident at the site (Fig. 3). Abundant pus was seen Lo exude from the recess of the ulcer.

With a diagnosis of gastric ulcer, probably the seat of confined perforation, abdominal laparotomy was performed. This revealed ascites and thickening of the gastric antral wall but no extramural penetration. Intensive antibiotic treatment was begun, and the patient slowly recovered. 


\section{DISCUSSION}

The discovery of gas in the portal venous system denotes not a specific entity but points to a visceral lesion that usually requires urgent surgical exploration. ${ }^{1}$. Factors that predispose to accumulation of gas in the portal venous system include gastrointestinal mucosal injury that permits gas-forming microorganisms to gain access to the portal vein, ${ }^{2}$ gas embolism resulting from increased intraluminal pressure in distended bowel, ${ }^{3}$ and sepsis. In some cases, more than one factor may pertain. In our patient, mucosal injury and sepsis were present.

Among the conditions associated with portal venous gas, the most frequent (72\%) is ischemic bowel disease, such as that which occurs with mesenteric infarction, arterial and venous mesenteric thrombosis, and necrotizing enterocolitis in the infant. ${ }^{4}$ Other reported conditions include intra-abdominal abscess, ulcerative colitis (usually following barium enema ${ }^{1}$ or colonoscopy ${ }^{3}$ ), bowel obstruction with or without necrosis, gastric ulcer, acute hemorrhagic pancreatitis, diabetic ketoacidosis, ${ }^{1}$ Crohn's disease, ${ }^{2}$ acute gastric dilation, ${ }^{5}$ pneumatosis cystoides intestinalis, ${ }^{4}$ umbilical vein catheterization, the use of hydrogen peroxide enemas in infants to relieve meconium ileus, ${ }^{6}$ and following the administration of OKT-3, a monoclonal antibody that may induce immune deficiency and lead to sepsis. ${ }^{7}$

There are only three reported cases of gas in the portal vein as a complication of peptic ulcer disease. ${ }^{1-8}$ Our case is unique in that gastric mucosal ulceration and sepsis, which led to portal venous gas, were caused by an inadvertently swallowed toothpick.

A review of cases complicated by the accumulation of gas in the portal venous system indicates an overall mortality rate of $75 \%$. When portal venous gas occurs as a complication of a diagnostic or therapeutic procedure, the mortality is somewhat less. When the condition is recognized, consideration should be given to prompt surgical exploration; under exceptionally favorable circumstances, consideration may be given to supportive therapy and vigilant observation. ${ }^{1}$

\section{REFERENCES}

1. Liebman PR, Patten MT, Manny J, Benfield JR, Hechtman HB. Hepaticportal venous gas in adults: etiology, pathophysiology and clinical significance. Ann Surg 1978;187:281.

2. Huycke A, Moeller DD. Hepatic portal venous gas after colonoscopy in granulomatous colitis. Am J Gastroenterol 1985;80:637.

3. Haber I.Hepatic portal vein gas following colonoscopy in ulcerative colitis: report of a case. Acta Gastroenterol Belg 1983;46:14.

4. Pappas D, Romeu J, Tarkin N, Dave PB, Messer J. Portal vein gas in a patient with Crohn's colitis. Am J Gastroenterol 1984;79:728.

5. Radin DR, Rosen RS, Halls JM. Acute gastric dilatation: a rare cause of portal venous gas. Am J Roentgenol 1987;148:279.

6. Sisley JF, Miller DM, Nesbit RR. Computerized axial tomography (CT) as an aid in the diagnosis of hepatic portal venous gas: a case report. Surgery 1987;101:376.

7. Waymack JP, Penn I, First MR, Alexander JW. Portal vein gas and sepsis after administration of OKT-3. Lancet 1987;1:984.

8. Rigler LG, Pogue WL. Roentgen signs of intestinal necrosis. Am J Roentgenol 1965;94:402. 


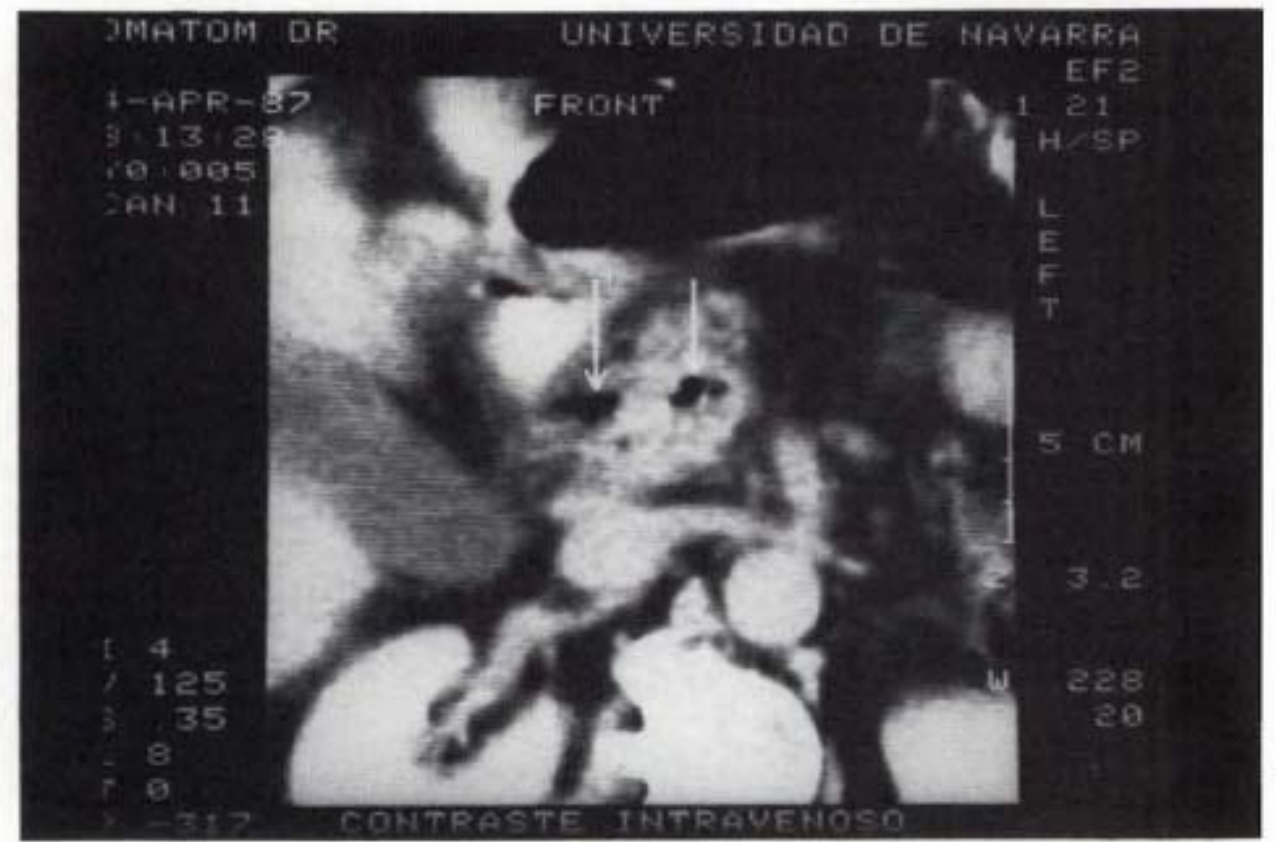

Figure 1. Abdominal CT showing gas in the portal venous system (arrows).

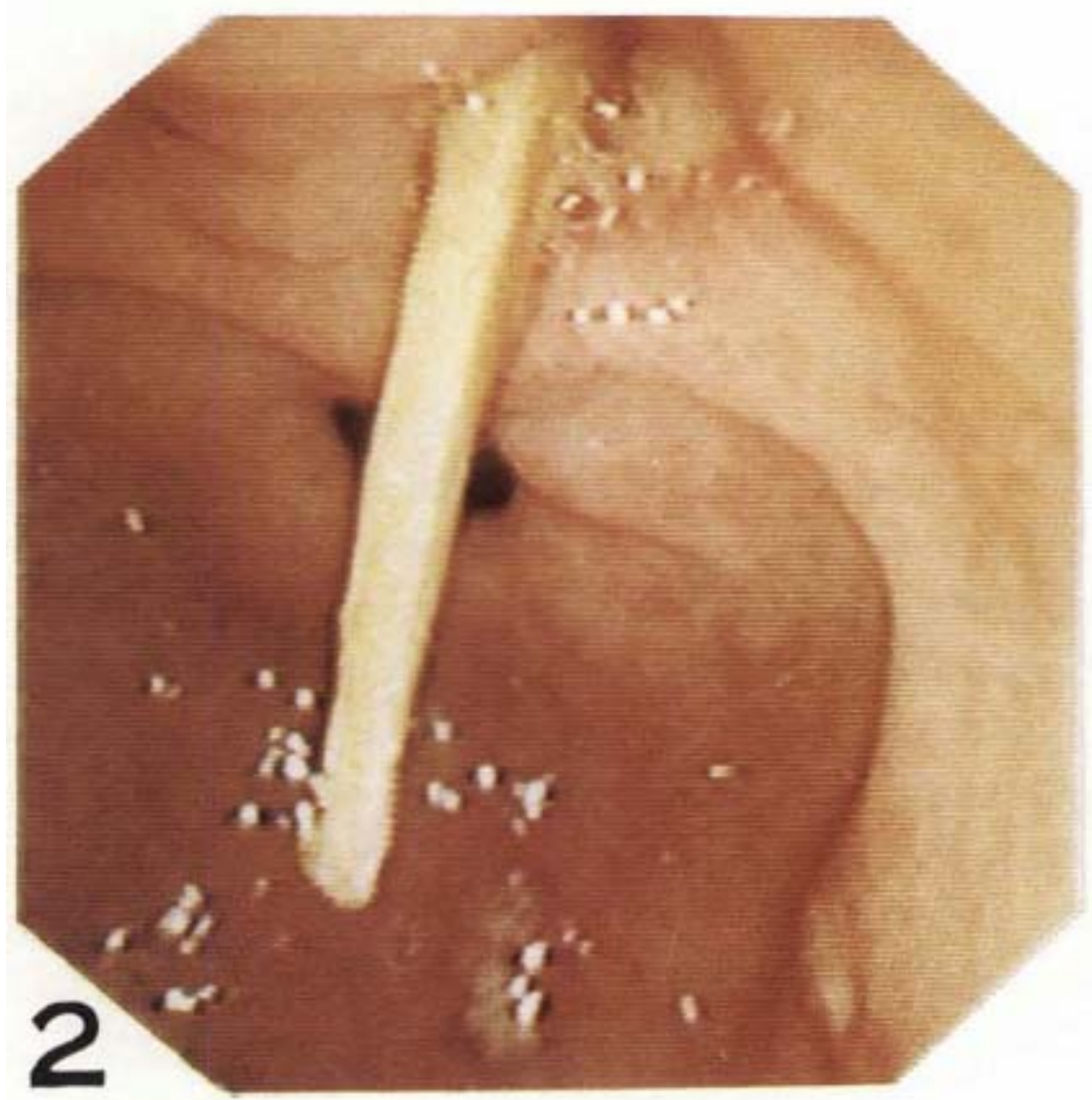

Figure 2. Toothpick embedded in the gastric antrum. 


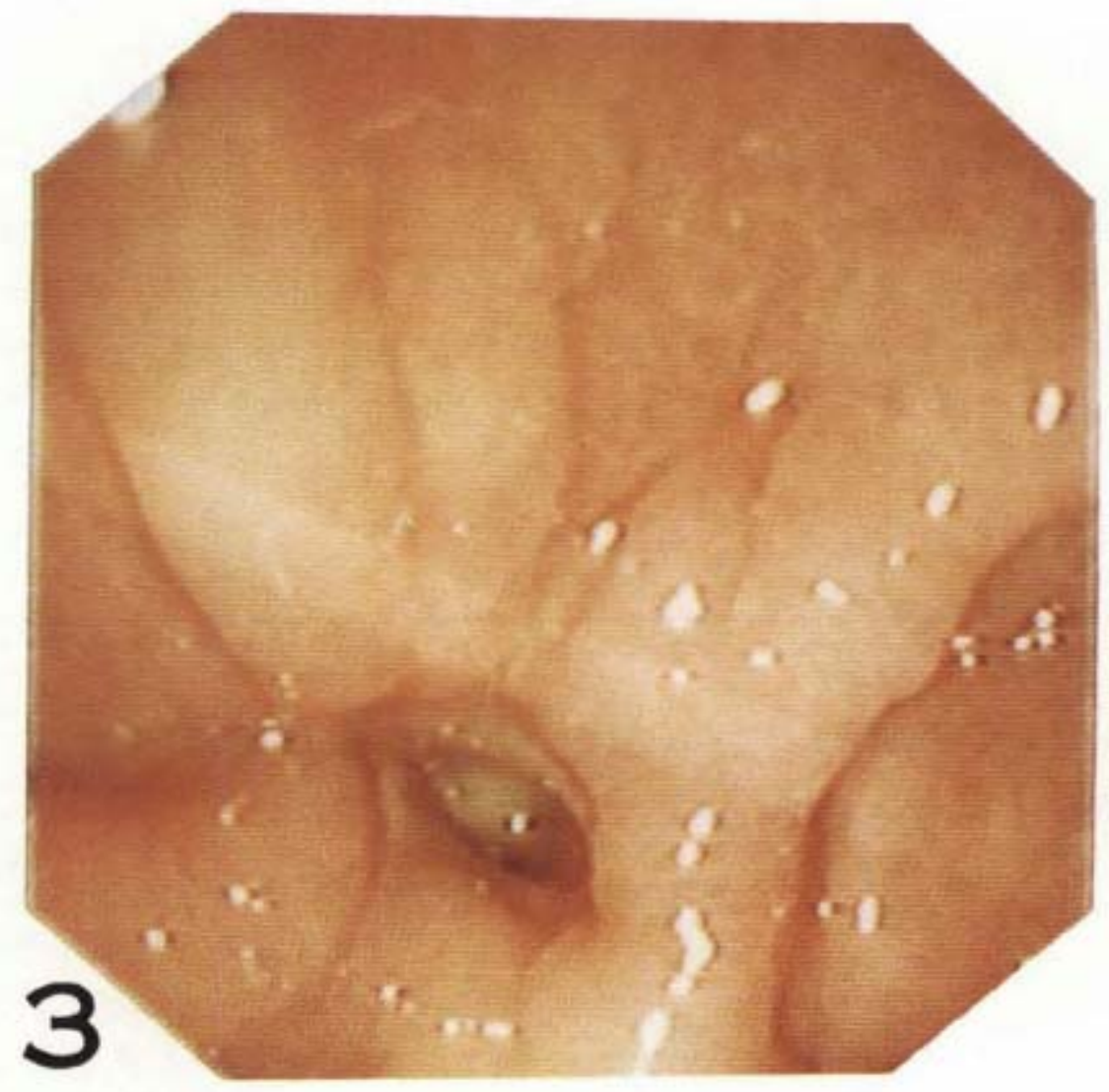

Figure 3. Deep gastric ulcer containing purulent fluid seen after toothpick removal. 